\title{
ВПЛИВ НАПОВНЕНИХ МІЦЕЛ ПАР НА МЦЦНСТЬ ДРІБНОЗЕРНИСТОГО БЕТОНУ
}

\section{INFLUENCE OF UPPER MICKSELS OF SOIL ON DENSITY DRYBOARD CONCRETE}

\begin{abstract}
Шишкіна О.О., к.т.н., доц., Шишкін О.О., д.т.н., проф. (Криворізький національний університет)
\end{abstract}

Shishkina O.O., Ph.D. in Engineering, Associate Professor, Shishkin O.O, Doctor of Engineering, Professor (Kryvyi Rih National University)

Визначено вплив наповнених акриловим латексом міцел гідрофобних колоїдних поверхнево-активних речовин на міцність дрібнозернистого бетону. Доведено підвищення міцності означеного бетону та залежність іiі величини від водоцементного відношення та кількості наповнених акриловим латексом міцел гідрофобних колоїдних поверхнево-активних речовин.

The effect of acrylic latex micelles of hydrophobic colloidal surfactants on the strength of fine-grained concrete has been investigated in this work. At this time, a steady trend has been the application of various types of catalysis to almost all reactions that are used in chemical technology. It should be noted that the use of catalytic methods to improve the effectiveness of chemical reactions has a special peculiarity. Such transformations are complex systems within the network of subreaccounts, so traditional methods of accelerating chemical processes, in particular the use of high temperatures, acids or bases, often do not give the desired result. Micelles of hydrophobic surfactants have an interesting and very valuable property: they can bind different molecules and ions. The micelles provide transportation of insoluble specimens due to unfavorable in other cases the phase of the solution. For example, using micelle transport substances can be used to accelerate maturation and growth of crystals. The purpose of this work is, for example, the use of acrylic latex to demonstrate the possibility of using a micelle filled organic substance of hydrophobic surfactants of an 
aliphatic type as a means of controlling the strength of fine-grained concrete. To achieve this goal, the task was to investigate the change in the strength of fine-grained concrete from the contents of a micelle filled with acrylic latex. As a result of the performed experiments, it was established that the introduction of acrylic latex into the concrete structure leads to a significant increase in the strength of concrete under compression. It is proved to increase the strength of the specified concrete and its dependence on the water-cement ratio and the amount of micelles filled with acrylic latex of hydrophobic colloidal surfactants. The optimum amount of acrylic latex in concrete, which provides the maximum increase in its compressive strength, depends on the watercement ratio in it and decreases with an increase in the water-cement ratio. The value of the relative strength of concrete in compression when introduced into its composition, the acrylic latex ash increases with decreasing the water-cement ratio.

Ключові слова: бетон, міцели, акрил, міцність, поверхневоактивні речовини.

Keywords: concrete, micelles, acrylic, strength, surface-active substances.

В останні роки відзначається різке збільшення інтересу до багатокомпонентних реакцій (БКР). Стійкою тенденцією стало застосування різних видів каталізу практично до всіх реакцій, які використовуються в органічній хімії, у тому числі й до БКР. Навіть ті перетворення, які раніше проводилися без використання якихнебудь каталізаторів, зараз залучені в коло каталітичних процесів, що відбиває загальний генеральний напрямок на підвищення ефективності органічного синтезу.

\section{Аналіз останніх досліджень}

Слід зазначити, що застосування каталітичних методів для підвищення ефективності БКР має особливу специфіку. Подібні перетворення являють собою складні системи, що входять до мережі субреакцій, тому традиційні методи прискорення хімічних процесів (використання високих температур, кислот або основ) найчастіше не дають бажаного результату [1]. Зазвичай вони діють неселективно, прискорюючи побічні двокомпонентні реакції, 
приводячи до появи небажаних продуктів у системі. 3 іншого боку, одним з недоліків багатьох БКР є їхня низька швидкість.

Супрамолекулярні системи на основі дифільних з'єднань (ПАР, гідрофобізованих макроциклів, полімерів та ін.) широко застосовуються в сучасних наукоємних технологіях [2]. Інтерес до цих систем обумовлений двома важливими властивостями дифільних з'єднань: здатністю до утворення агрегатів в розчині вище певної концентрації (у разі розчинів ПАР званої критичної концентрацією міцелоутворення, ККМ), а також солюбілізуючими властивостями агрегатів щодо органічних і біологічних субстратів [3]. Введення до складу системи «портландцемент - вода» димерів гідрофобних ПАР аліфатичного типу також призводить до значного збільшення міцності цементного каменя [4].

Міцели гідрофобних ПАР володіють цікавою і дуже цінною властивістю: вони можуть зв'язувати різні молекули і іони. Це явище (в загальному випадку зване солюбілізація) носить універсальний характер. Міцели ПАР знаходять широке застосування в якості міцелярних каталізаторів, переносників лікарських засобів і генного матеріалу, антимікробних препаратів, інгібіторів корозії i т.д. Міцели забезпечують транспорт нерозчинних зразків через несприятливу в інших випадках фазу розчину. Так, наприклад, за допомогою міцел транспорт речовин може бути використаний для прискорення дозрівання i росту кристалів.

Більшість робіт по застосуванню наночастинок для поліпшення характеристик бетону відноситься до $\mathrm{Fe}_{2} \mathrm{O}_{3}$ [5], $\mathrm{Al}_{2} \mathrm{O}_{3}$ [6] i $\mathrm{ZrO}_{2}$ [7]. Проводилися дослідження з використання наночастинок СuO [8], монтморилоніту [9] і каоліну [10], а в роботі [11] - використання порошків окислів металів $\mathrm{Ti}, \mathrm{Al}, \mathrm{Ca}, \mathrm{Mg}, \mathrm{W}, \mathrm{Co}$ та кремнію, застосованих у мікродозах. Означені роботи присвячено застосуванню наповнених оксидами металів міцел ПАР, i відносяться до технології «золь - гель».

Наведений досвід застосування технології «золь - гель» тобто наповнених неорганічними речовинами міцел для регулювання міцності бетону [5-11] підтверджує актуальність досліджень в цьому напряму із застосуванням міцел наповнених органічними речовинами. 


\section{Постановка мети і задач досліджень}

Метою даної роботи є на прикладі застосування акрилового латексу показати можливість використання наповнених органічною речовиною міцел гідрофобних ПАР аліфатичного типу як засобу управління міцністю дрібнозернистих бетонів.

Для досягнення означеної мети в роботі була поставлена задача дослідити зміну міцності дрібнозернистого бетону від вмісту в ньому міцел, наповнених акриловим латексом.

\section{Методика досліджень}

Для проведення дослідів використовували портландцемент ПАТ «Хайдельберг цемент. Кривий Ріг» марки ПЦ М400-Д20, в якості міцелоутворюючої ПАР застосовували олеат натрію, в якості дрібного заповнювача бетону використовували Дніпровський річковий пісок, в якості наповнювача бетону - мелений доменний гранульований шлак.

Наповнені міцели готували шляхом розчинення у воді олеату натрію 3 наступним додаванням при постійному перемішуванні акрилового латексу.

Отриманий водяний розчин наповнених акриловим латексом міцел (ае) додавали до води при отриманні бетону.

3 дрібнозернистого бетону, який містив або тільки наповнювач у кількості 30\% від маси мінеральної частини бетону, або наповнювач у кількості $30 \%$ від міси суміші портландцементу і наповнювача та заповнювач у кількості 75 \% від маси мінеральної частини бетону.

Для випробування виготовляли зразки бетону розміром 40x40x160 мм., які після виготовлення тверділи на протязі певного часу, після чого піддавалися випробуванням на стиск за стандартними методиками випробувань зразків бетону за допомогою універсальної випробувальної машини УММ-100.

\section{Результати досліджень. У результаті виконаних} експериментів встановлено, що введення до складу бетону золю акрилового латексу призводить до значного збільшення міцності бетону при стиску (рис.1,2,3).

Аналіз результатів експериментів показав, що ступінь впливу золю акрилового латексу на міцність бетону залежить не тільки від його кількості в складі бетону, а й від величини водоцементного відношення в бетоні (тобто від кількості води). 
"Сучасні технології та методи розрахунків у будівництві", випуск 11, 2019

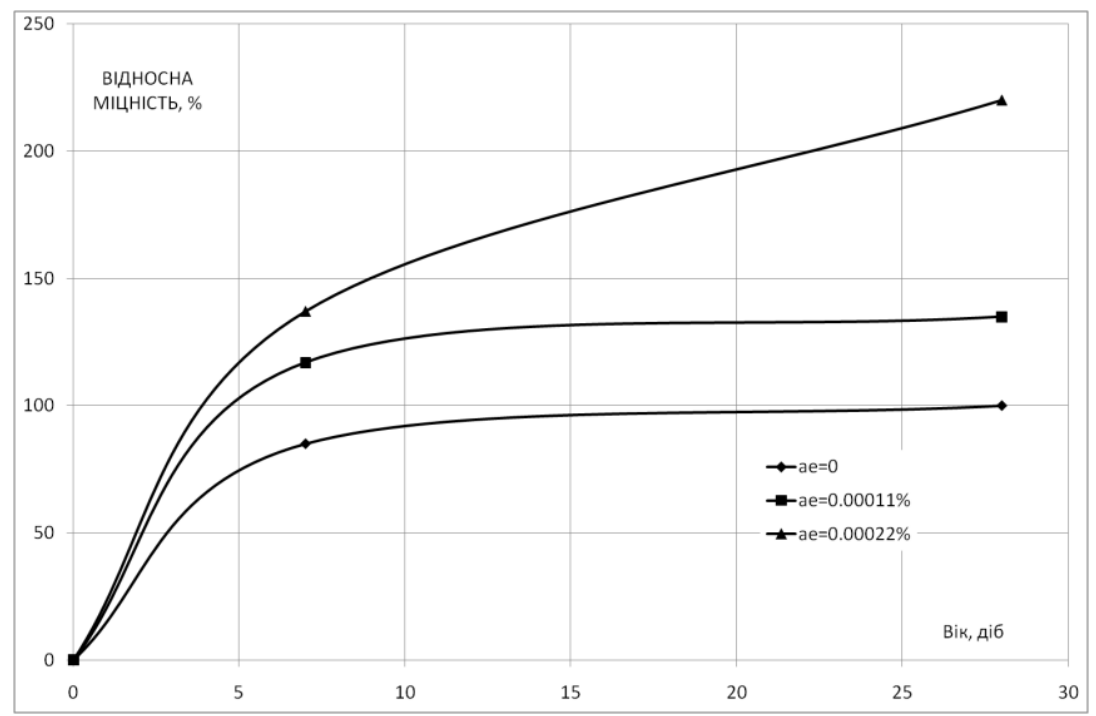

Рис. 1 Відносна міцність бетону без дрібного заповнювача при $\mathrm{B} / Ц=0,3$

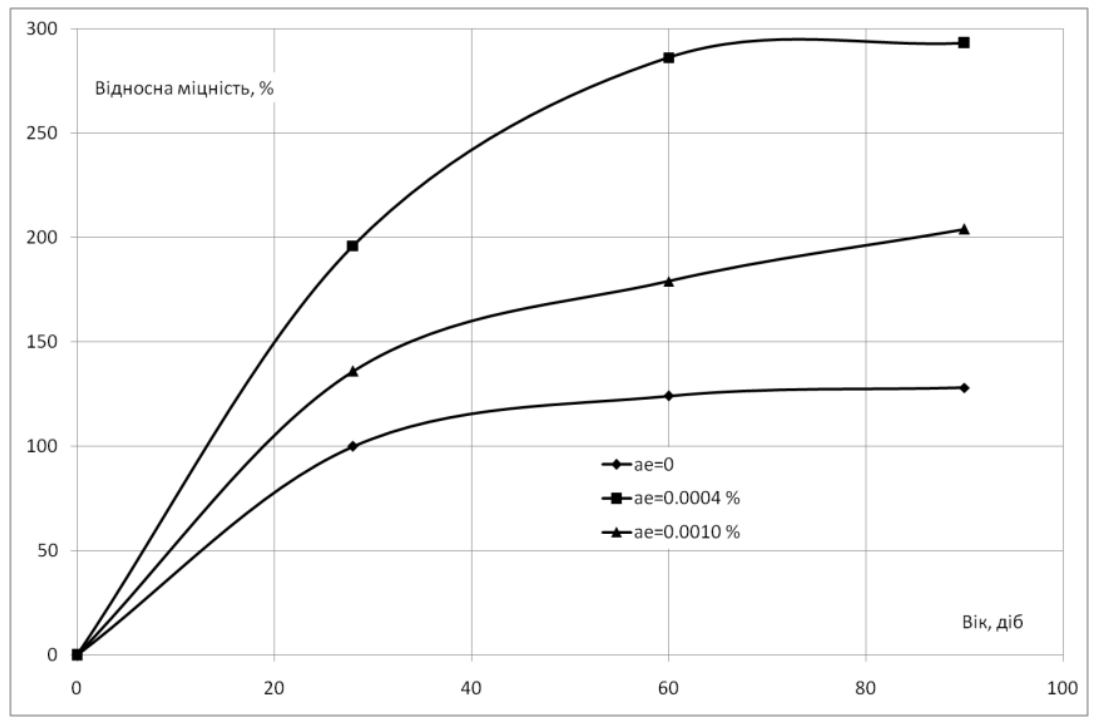

Рис. 2. Відносна міцність бетону із дрібним заповнювачем при $\mathrm{B} / Ц=0,4$ 


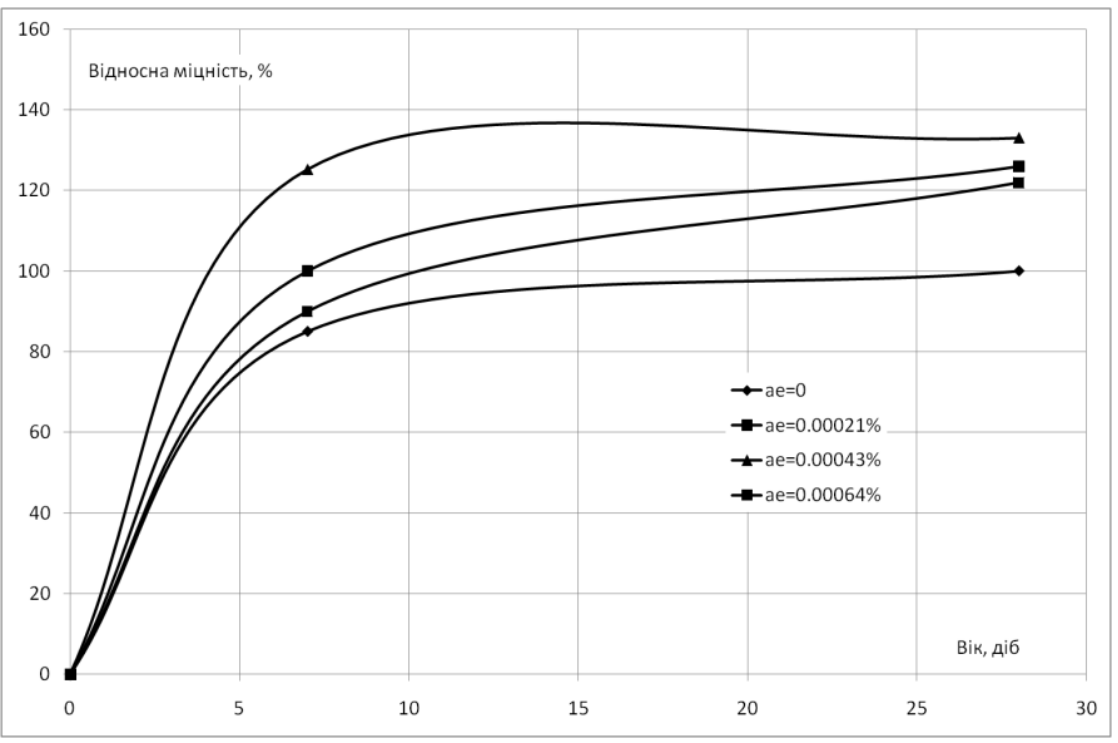

Рис. 3. Відносна міцність бетону без дрібного заповнювача при $\mathrm{B} / Ц=0,5$

Так при водоцементному відношенні 0,3 максимальний приріст міцності бетону складає у віці 28 діб $120 \%$ (рис. 1), при водоцементному відношенні 0,4 максимальний приріст міцності бетону складає у віці 28 діб 100\% (рис.3), а при водоцементному відношенні 0,5 максимальний приріст міцності бетону складає у віці 28 діб тільки $38 \%$ (рис.2).

Означене підтверджує гіпотезу щодо відповідності процесів, що відбуваються у даному випадку в розглянутій системі, «гель золь технології».

Цей же висновок підтверджують і результати дослідження впливу вмісту наповнений міцел в бетоні на його міцність (рис. 4).

Аналіз результатів досліджень даної групи експериментів показує, що із збільшенням водоцементного відношення зменшується вплив наповнених міцел на міцність бетону. Окрім 
того, зменшується кількість наповнених міцел, яка забезпечує максимальне збільшення міцності бетону (рис. 4).

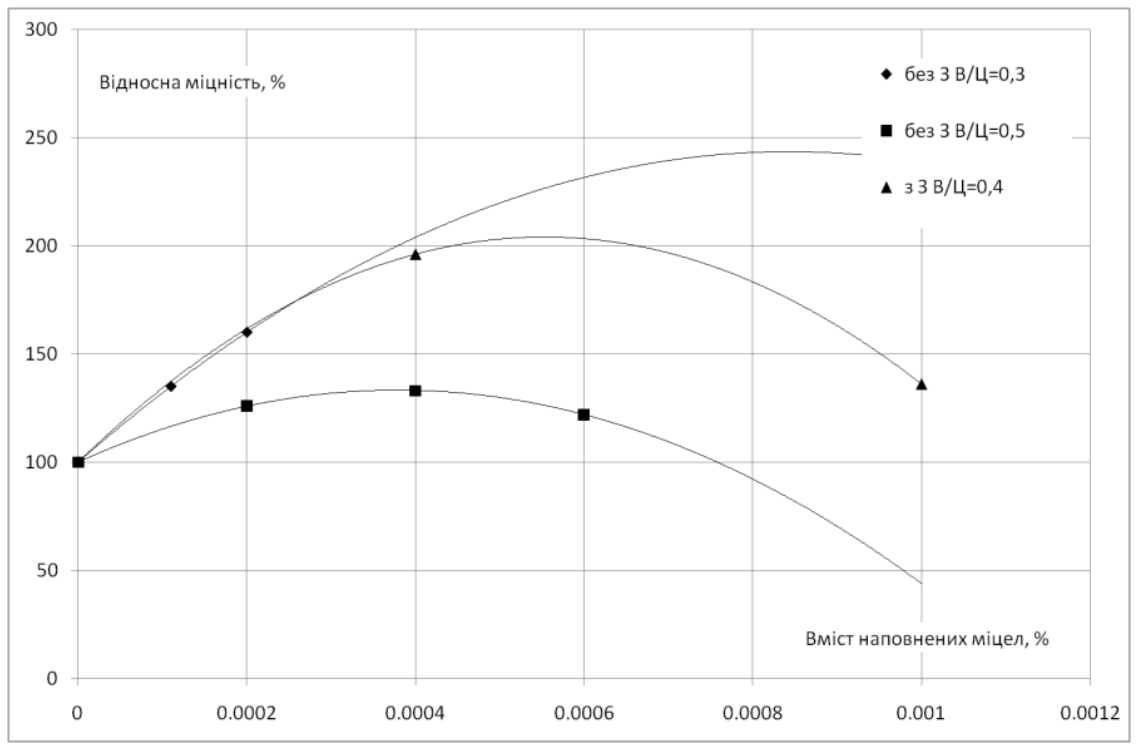

Рис. 4. Вплив наповнених міцел на міцність бетону (3 - заповнювач)

\section{Висновки}

Виконані дослідження дозволяють зробити наступні висновки:

1. Використання золю органічної речовини як добавки до дрібнозернистого бетону дозволяє керувати величиною його міцності при стиску. Процеси, які обумовлюють означене, відносяться до «золь - гель» технології.

2. Оптимальна кількість золю органічної речовини в бетоні, яка забезпечує максимальне збільшення його міцності при стиску, залежить від водоцементного відношення в ньому і зменшується із збільшенням водоцементного відношення.

3. Величина відносної міцності бетону при стиску при введенні до його складу золю органічної речовини збільшується при зменшенні водоцементного відношення. 


\section{Список використаних джерел}

1. Л. Я. Захарова, А. И. Коновалов. Супрамолекулярные системы на основе катионных поверхностно-активных веществ и дифильных макроциклов. Коллоидный журнал, 2012, том 74, № 2, с. 209-221. 2. Sanchez F., Sobolev K. Nanotechnology in concrete - A review. - Construction and Building Materials., 2010, №24, p.2060-2071. 3. Li H., Zhang M-H., Ou JP. Flexural fatigue performance of concrete containing nano-particles for pavement. Int. J. Fatig., 2007, v.29, №7, p.1292-1301. 4. Shishkina A., Shishkin A. Research into effect of complex nanomodifiers on the strength of finegrained concrete. Eastern-European Journal of Enterprise Technologies 2/6 (92) 2018. p. 29 - 33. 5. Abdoli N., Arefi R., Mollaahmadi E., Abdollahi B. To study the effect of adding $\mathrm{Fe}_{2} \mathrm{O}_{3}$ nanoparticles on the morphology properties and microstructure of cement mortar. Life Science Journal., 2011, v.8, №4, p.550554. 6. Li Z., Wang H., He S., Lu Y., Wang M. Investigations on the preparation and mechanical properties of the nano-alumina reinforced cement composite. Mater. Lett. V., 2006, v.60, №3, p.356-359. 7. Nazari A., Riahi H. The effects of $\mathrm{ZrO}_{2}$ nanoparticles on physical and mechanical properties of high strength self compacting concrete. Materials Research., 2010, v.3, №4, p.1-13. 8. Nazari A., Riahi H. Effects of $\mathrm{CuO}$ nanoparticles on compressive strength of self-compacting concrete. Sadhana., June 2011, v.36, Part 3, p.371-391. 9. Chang T-P, Shih J-Y, Yang K-M, Hsiao T-C. Material properties of Portland cement paste with nano-montmorillonite. J. Mater. Sci., 2007, v.42, №17, p.7478-7487. 10. Шишкина А.А., Шишкин А.А. Влияние модифицированного каолина на прочность порошкового бетона. Науковий вісник будівництва. 2018. 1(91). С. 169-172. 11. Тевяшев А.Д., Шитиков Е.С. О возможности управления свойствами цементобетонов с помощью нано-модификаторов. Восточно-европейский журнал передовых технологий. 2009. 4/7 (40). С. 35-40. 